\title{
The Epidemiology of Stevens-Johnson Syndrome and Toxic Epidermal Necrolysis in China
}

\author{
Shang-Chen Yang $\mathbb{D}^{1},{ }^{1}$ Sindy Hu $\mathbb{D D}^{1,2}$ Sheng-Zheng Zhang $(\mathbb{D}){ }^{1}$ Jin-wen Huang $(\mathbb{D})^{3}$ \\ Jing Zhang $(\mathbb{D})^{3}$ Chao Ji $\mathbb{D}^{3},{ }^{3}$ and Bo Cheng $\mathbb{D}^{3}$ \\ ${ }^{1}$ Department of Dermatology, Xiamen Chang Gung Hospital, Xiamen, Fujian, China \\ ${ }^{2}$ Department of Dermatology, Chang Gung Memorial Hospital, Chang Gung University, Taoyuan, Taiwan \\ ${ }^{3}$ Department of Dermatology, The First Affiliated Hospital of Fujian Medical University, Fuzhou, Fujian, China
}

Correspondence should be addressed to Chao Ji; surpassing_ji@aliyun.com and Bo Cheng; chengbo630415@126.com

Received 31 August 2017; Revised 8 November 2017; Accepted 28 November 2017; Published 11 February 2018

Academic Editor: Yi-Giien Tsai

Copyright (c) 2018 Shang-Chen Yang et al. This is an open access article distributed under the Creative Commons Attribution License, which permits unrestricted use, distribution, and reproduction in any medium, provided the original work is properly cited.

\begin{abstract}
Stevens-Johnson syndrome and toxic epidermal necrolysis (SJS/TEN) are life-threatening disease. However, there are only few epidemiologic studies of SJS/TEN from China. To analyze the clinical characteristics, causality, and outcome of treatment for SJS/TEN in China, we reviewed case reports of patients with SJS/TEN from the China National Knowledge Infrastructure (CNKI) and Wanfang database from 2006 to 2016 and patients with SJS/TEN who were admitted to the First Affiliated Hospital of Fujian Medical University during the same period. There were 166 patients enrolled, including 70 SJS, 2 SJS/TEN overlap, and 94 TEN. The most common offending drugs were antibiotics (29.5\%) and anticonvulsants (24.1\%). Carbamazepine, allopurinol, and penicillins were the most common single offending drugs (17.5\%, 9.6\%, and 7.2\%). Chinese patent medicines accounted for 5.4\%. There were 76 (45.8\%) patients receiving systemic steroid and intravenous immunoglobulin (IVIG) in combination therapy, especially for TEN (80.3\%), and others were treated with systemic steroids alone. Mortality rate of combination treatment comparing with steroid alone in TEN patients had no statistical significance. In conclusion, carbamazepine and allopurinol were the leading causative drugs for SJS/TEN in China. Combination of IVIG and steroids is a common treatment for TEN, but its efficacy in improving mortality needs further investigation.
\end{abstract}

\section{Introduction}

Stevens-Johnson syndrome/toxic epidermal necrolysis (SJS/ TEN) is a well-known severe cutaneous adverse reaction (SCAR) belonged to type IV hypersensitivity, mediated by immunological effect [1]. This hypersensitivity reaction is recognized as a dysregulation of cellular immunity [2], caused by a release of various cytotoxic signals including granulysin [3], perforin/granzyme B, and Fas/Fas ligand [4] which were activated by cytotoxic $\mathrm{T}$ lymphocytes and natural killer cells. SJS/TEN refers to a spectrum with widespread epidermal detachment and mucocutaneous involvement [5]. Different total body surface areas (TBSA) of detached or detachable skin lesions as $<10 \%, 10-30 \%$, and $>30 \%$ are representing Stevens-Johnson syndrome (SJS), SJS/TEN overlap (SJS-TEN), and toxic epidermal necrolysis (TEN) [6]. SCORTEN disease severity scoring system is widely used in assessing the mortality of SJS/TEN [7]. The mortality rates of SJS, SJS-TEN, and TEN were $5-10 \%, 30 \%$, and $50 \%$, respectively $[2,5]$. Recently, IL-15 has been found to be useful in predicting severity and monitoring prognosis [2]. A global population-based study had previously reported that the incidence of SJS and TEN is estimated 1.0 to 6.0 per million and 0.4 to 1.2 per million, respectively [8]. However, Frey et al. [9] estimated that Asian patients were at a 2fold risk of SJS/TEN when compared with Caucasian patients in their recent study. There are few English literatures related to SJS/TEN studies from China so far. 
In this study, we analyzed case reports of SJS/TEN from Chinese literatures and cases from a tertiary referral medical center from the past 10 years. The clinical characteristics, common drug causality, and outcome of treatments were analyzed.

\section{Methods}

We reviewed cases of SJS/TEN from the China National Knowledge Infrastructure (CNKI) and Wanfang Data [10-37] from January 2006 to December 2016. CKNI and Wanfang Data were well-known large comprehensive network full-text databases in China, established, respectively, since 1999 and 2000. Data from online database were searched by the key word of Stevens-Johnson syndrome and toxic epidermal necrolysis. All cases from databases were published in Chinese journals. We only enrolled cases which had detailed description of skin lesions, photographs, or histopathologic findings.

In addition, we also analyzed admission database from the First Affiliated Hospital of Fujian Medical University (FJMU) during 2006 to 2016. This hospital is the major tertiary referral medical center in Fujian Province and had total 4006 dermatology inpatients during this period. Data from admission database were searched by the diagnosis of Stevens-Johnson syndromes and toxic epidermal necrolysis. One patient from the FJMU has been published as a case report in Chinese literature.

All cases of SJS/TEN enrolled for this analysis from the CNKI, Wanfang Data, and FJMU fulfilled with RegiSCAR (European Registry of Severe Cutaneous Adverse Reactions) criteria of probable to definite cases. They were carefully assessed by at least two dermatologists and further validated by the Taiwan-SCAR consortium [38-40]. All cases met the criteria of SJS/TEN from databases, and the hospital had been double checked by sex, age, and causality to exclude overlapping. The drug causalities of enrolled cases were assessed by the ALDEN algorithm, only with probable or definite (ALDEN score $\geq 4$ ), and were included as druginduced SJS/TEN.

All cases in this study were Han Chinese. We analyzed the detailed information collected from reviewed literatures or medical records, including patient demographics (sex and age), offending drugs, underlying medical diseases, treatments, and outcomes. We also further compared the causality of SJS/TEN in China and Southeast Asia [41].

Statistical analyses were performed using SPSS for Windows version 21.0 (IBM, Armonk, NY). Fisher's exact tests were used for analysis. Odds ratio (OR) and 95\% confidence interval (CI) were also calculated. $P<0.05$ (two-tailed) was considered to be statistically significant.

\section{Results}

There were total 230 SJS/TEN cases collected from reported Chinese literatures and admission database from the First Affiliated Hospital of FJMU between 2006 and 2016. Totally,

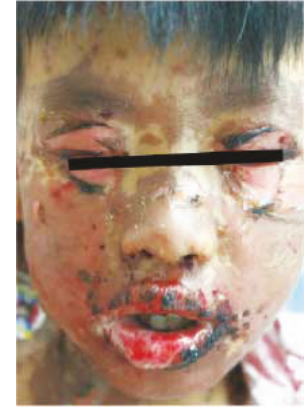

(a)

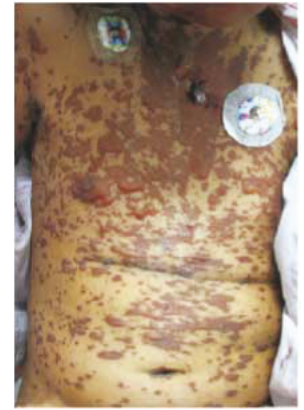

(b)
FIgURe 1: Typical cases of SJS from Chinese literature [20]. (a) Detachment of the eyelids, erosions and crusts of lips, and brownish macules on face and neck with scattered skin detachment. (b) Brownish macules with blisters and detachment on the trunk.

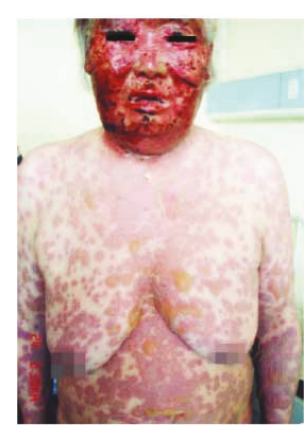

(a)

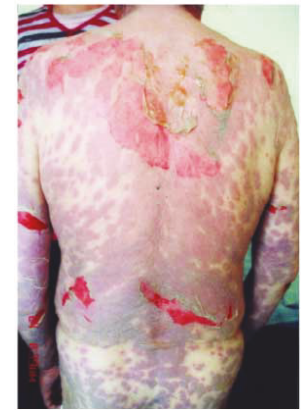

(b)
FIgure 2: Typical cases of TEN from Chinese literature [12]. (a) Widespread reddish to purplish macules and bullae on the trunk and upper limbs, with erosions on swollen face. (b) Macules and large skin detachment on the lateral trunk and upper limbs.

166 met the criteria of probable to definite cases of SJS/ TEN, including 94 cases from literatures and 72 cases from the hospital (incidence rate of hospital population was $1.8 \%)$. Among them, there were $70(42.2 \%)$ as SJS, 2 $(1.2 \%)$ as SJS-TEN, and $94(56.6 \%)$ as TEN. Typical cases of SJS and TEN from Chinese literature were shown in Figures 1 and 2 .

\subsection{Demographic Data, Treatment, and Prognosis of Patients} with SJS/TEN. The demographic and characteristics are summarized in Table 1. The age of the onset of SJS/TEN ranged from 1 to 94 years. Mean age of both SJS/TEN is over 40 years, with SJS or SJS-TEN in 43.4 years, and TEN in 43.6 years. There were $46(63.9 \%)$ males and $26(36.1 \%)$ females diagnosed with SJS or SJS-TEN and $54(57.4 \%)$ male and 40 (42.6\%) females diagnosed with TEN. There were 4 patients that were found to have HIV positive. All the enrolled patients received systemic corticosteroid, mostly methylprednisolone $(67.8 \pm 38.4 \mathrm{mg} / \mathrm{d})$. Among these 166 cases, 76 (45.8\%) patients had additional intravenous immune globulin (IVIG) $(0.5 \pm 0.3 \mathrm{~g} / \mathrm{kg} / \mathrm{d}), 11$ patients received steroid pulse therapy (methylprednisolone $300-500 \mathrm{mg} / \mathrm{d}$ ), 1 patient had cyclophosphamide, and 1 patient had plasmapheresis. 
TABle 1: Demographic data, treatment, and prognosis patients with SJS/TEN.

\begin{tabular}{lccccccc}
\hline & $\begin{array}{c}\text { SSS or SJS-TEN } \\
(n=72)\end{array}$ & $\begin{array}{c}\text { SJS } \\
(n=70)\end{array}$ & $\begin{array}{c}\text { SJS-TEN } \\
(n=2)\end{array}$ & $\begin{array}{c}\text { TEN } \\
(n=94)\end{array}$ & $\begin{array}{c}\text { Total } \\
(n=166)\end{array}$ & $\begin{array}{c}\text { Odds ratio } \\
(95 \% \text { CI })\end{array}$ & $P$ values \\
\hline Age, $y$ & & & & & & & 0.967 \\
$\quad$ Mean \pm SD & $43.4 \pm 21.7$ & $43.5 \pm 21.9$ & $40.5 \pm 11.5$ & $43.6 \pm 22.7$ & $43.5 \pm 22.3$ & - & - \\
$\quad \begin{array}{l}\text { Median (range) } \\
\text { Sex, } n \text { (\%) }\end{array}$ & $48(1-93)$ & $48(1-93)$ & $40.5(29-52)$ & $44.5(1-94)$ & $45(1-94)$ & - & \\
$\quad$ Male & $46(63.9)$ & $46(65.7)$ & $0(0)$ & $54(57.4)$ & $100(60.2)$ & $0.427(0.406-1.435)$ & 0.763 \\
IVIG in combination, $n(\%)$ & $15(20.8)$ & $14(20.0)$ & $1(50)$ & $61(64.9)$ & $76(45.8)$ & $7.024(3.456-14.275)$ & $<0.001$ \\
Pulse therapy & $4(5.6)$ & $3(4.3)$ & $1(50)$ & $7(7.4)$ & $11(6.6)$ & $0.731(0.206-2.600)$ & 0.758 \\
Death, $n(\%)$ & $1(1.4)$ & $1(1.4)$ & $0(0)$ & $8(8.5)$ & $9(5.4)$ & $6.605(0.807-54.071)$ & 0.079 \\
\hline
\end{tabular}

IVIG: intravenous immune globulin; SJS: Stevens-Johnson syndrome; SJS-TEN: SJS/TEN overlap; TEN: toxic epidermal necrolysis.

3.2. Causality of SJS/TEN. We categorized the causality into 9 groups in Table 2. The commonest causative drug category for SJS/TEN was antibiotics in 49 (29.5\%) patients, and $75.5 \%$ of them were diagnosed with TEN. The largest proportion of the identified single offending antibiotics was penicillins $(7.2 \%)$, followed by cephalosporins (4.2\%) and quinolones (3.6\%). Many of the patients had concomitant use with multiple antibiotics (4.8\%). The second common offending drug category was anticonvulsants $(n=40$, $24.1 \%$ ), which the leading cause was carbamazepine (17.5\%), followed by lamotrigine (4.2\%), oxcarbazepine (1.2\%), phenobarbital (0.6\%), and phenytoin (0.6\%). Three patients among them had undergone HLA genotyping, one carbamazepine-TEN and one oxcarbazepine-SJS carried the risk $H L A-B^{*} 15: 02$ allele, and the other carbamazepine-SJS carried HLA-B* 51:01/15:11 without $H L A-B^{*} 15: 02$. Allopurinol contributed 16 (9.5\%) patients, 2 of them had received HLA genotyping and revealed $H L A-B^{*} 58: 01$ positive.

Chinese patent medicines accounted for 9 (5.4\%) cases, mostly were compound preparations. Three were for cold or clearing heat, including cough granule (containing loquat, opium poppy husk, stemona, mulberry bark, swallowwort rhizome, etc.), bupleurum granule (containing bupleurum, Pinellia ternata with ginger, radix scutellariae, Codonopsis pilosula, etc.), and extract of Andrographis paniculata. Others were sleeping capsule (containing lilium, Acanthopanax senticosus, caulis polygoni multiflori, Albizia julibrissin durazz, mother-of-pearl, etc.), Gutong capsule (containing ginseng, resina draconis, scorpion, bungarus minimus, etc.), and Honghua tablet (containing Emilia sonchifolia, Hedyotis diffusa, caulis spatholobi, etc.), and the last three were unspecified.

There were $8(4.8 \%)$ cases caused by nonsteroidal antiinflammatory drugs (NSAIDs), including diclofenac, ibuprofen, analgin, and some compound which contained paracetamol, caffeine, and aspirin, or aminopyrine, or phenacetin. Ten $(6.0 \%)$ patients have taken multiple drugs concomitantly for treating common cold, including different combinations of antibiotics, anticonvulsant, NSAIDs, and Chinese patent drugs. There were $3(1.8 \%)$ patients caused by industrial chemicals, which were acetochlor, naphthalenedisulfonic acid dimethyl ester, and trichloroethylene. Finally, 12 (7.2\%) patients were caused by other drugs, including methazolamide $(n=8)$, dobesilate $(n=1)$, antifungals $(n=1)$, antidepressant $(n=1)$, and antituberculosis drugs $(n=1)$. One patient using methazolamide had HLA genotyping and was found to be $H L A-B^{*}$ 59:01 positive. However, 19 (11.4\%) patients had no offending drug identified and no known infections.

The distribution of offending drugs causing SJS/TEN in northern or southern China was similar in which antibiotics (30.4\% versus $29.2 \%)$ and anticonvulsants $(28.3 \%$ versus $22.5 \%$ ) were of most causative categories. However, there were more cases of allopurinol-related SJS/ TEN in southern China (11.7\% versus $4.3 \%)$ and more NSAID-related cases in northern China (8.7\% versus 3.3\%) (Table 3).

We further compared the drug causality of SJS/TEN in China to that in Southeast Asia, and the result was shown in Table 4. The proportion of antibiotics or anticonvulsantrelated SJS/TEN of Malaysia (27.8\% and 33.3\%) and Singapore $(28.9 \%$ and $29.6 \%)$ was similar to that of China (29.5\% and 24.1\%), Thailand had higher percentage of antibiotic-related SJS/TEN (66.7\%), and the Philippines had higher percentage of anticonvulsant-related SIS/TEN (42.9\%). Penicillins were the most common causative antibiotics in China in our study (7.2\%), which are similar to Singapore (11.9\%) and Thailand (31.7\%), whereas sulfonamide being the largest group of antibiotics in Malaysia (17.3\%) and the Philippines (7.1\%). Carbamazepine was the most common causative anticonvulsant in our study $(17.5 \%)$ and also in other Southeast Asian countries (Table 4). Allopurinol was also one of the leading causes for SJS/TEN in Asian countries (China: 9.6\%, Philippines: 21.4\%, and Singapore: 20.4\%). Interestingly, Chinese patent medicines, or herbal medicines, which are still common traditional therapeutics in Chinese society, caused 7.5\% SJS/ TEN in Singapore, $5.4 \%$ of our study in China, and 3.6\% and $2.5 \%$ in the Philippines and Malaysia, respectively.

3.3. Mortality of SJS/TEN. There were 9 (5.4\%) deceased patients (Table 5), 1 was SJS, and 8 were TEN. Patient diagnosed with SJS was a 51-year-old male, with underlying disease of chronic renal failure and diabetes, and had cardiorespiratory arrest before admission. Other 8 patients diagnosed with TEN mostly had cardiovascular disease, diabetes, and nephropathy. Besides a child with age of 3 
TABLE 2: Drug causality of SJS/TEN in China.

\begin{tabular}{|c|c|c|c|c|}
\hline & $\begin{array}{c}\text { SJS or SJS-TEN, } n(\%) \\
(n=72)\end{array}$ & $\begin{array}{l}\text { TEN, } n(\%) \\
\quad(n=94)\end{array}$ & $\begin{array}{l}\text { Total, } n(\%) \\
\quad(n=166)\end{array}$ & $\begin{array}{c}\text { Death, } n \\
(n=9)\end{array}$ \\
\hline \multicolumn{5}{|l|}{ Culprit drug } \\
\hline Allopurinol & $11(15.3)$ & $5(5.3)$ & $16(9.6)$ & 2 \\
\hline Antibiotics & $12(16.7)$ & $37(39.4)$ & $49(29.5)$ & 5 \\
\hline Penicillins $^{\mathrm{a}}$ & 2 & 10 & 12 & 1 \\
\hline Cephalosporins $^{\mathrm{b}}$ & 1 & 6 & 7 & 1 \\
\hline Carbapenems $^{c}$ & 0 & 3 & 3 & 0 \\
\hline Quinolones $^{\mathrm{d}}$ & 3 & 3 & 6 & 0 \\
\hline Sulphonamides ${ }^{\mathrm{e}}$ & 3 & 1 & 4 & 0 \\
\hline Others $^{\mathrm{f}}$ & 2 & 4 & 6 & 0 \\
\hline Unspecified $^{\mathrm{g}}$ & 1 & 2 & 3 & 1 \\
\hline Multiple drugs ${ }^{\mathrm{h}}$ & 0 & 8 & 8 & 2 \\
\hline Anticonvulsants & $19(26.4)$ & $21(22.3)$ & $40(24.1)$ & $\mathbf{0}$ \\
\hline Carbamazepine & 12 & 17 & 29 & 0 \\
\hline Lamotrigine & 4 & 3 & 7 & 0 \\
\hline Others $^{\mathrm{i}}$ & 3 & 1 & 4 & 0 \\
\hline Chinese patent medicines ${ }^{\mathrm{j}}$ & $6(8.3)$ & $3(3.2)$ & $9(5.4)$ & $\mathbf{0}$ \\
\hline Industrial chemicals ${ }^{\mathrm{k}}$ & $0(0)$ & $3(3.2)$ & $3(1.8)$ & $\mathbf{0}$ \\
\hline NSAIDs $^{1}$ & $3(4.2)$ & $5(5.3)$ & $8(4.8)$ & $\mathbf{0}$ \\
\hline Multiple drugs ${ }^{\mathrm{m}}$ & $3(4.2)$ & $7(7.4)$ & $10(6.0)$ & 1 \\
\hline Others $^{\mathrm{n}}$ & $7(9.7)$ & $5(5.3)$ & $12(7.2)$ & 1 \\
\hline Nondrugs $^{\circ}$ & $11(15.3)$ & $8(8.5)$ & $19(11.4)$ & 0 \\
\hline
\end{tabular}

NSAIDs: nonsteroidal anti-inflammatory drugs; SJS: Stevens-Johnson syndrome; SJS-TEN: SJS/TEN overlap; TEN: toxic epidermal necrolysis. ${ }^{a}$ Penicillins including amoxicillin $(n=5)$, amoxicillin with clavulanic acid $(n=1)$, ampicillin $(n=1)$, penicillin $(n=1)$, piperacillin $(n=1)$, and piperacillintazobactam $(n=3)$. ${ }^{\mathrm{b} C e p h a l o s p o r i n s ~ i n c l u d i n g ~ c e f a l e x i n ~}(n=1)$, cefaclor $(n=1)$, cefuroxime $(n=2)$, cefoperazone sulbactam $(n=2)$, and cefotaxim $(n=1) .{ }^{\mathrm{C}}$ Carbapenems including imipenem-cilastatin $(n=2)$ and meropenem $(n=1) .{ }^{\mathrm{d}}$ Quinolones including ciprofloxacin $(n=1)$ and levofloxacin $(n=5)$. eSulphonamides including sulfasalazine $(n=2)$, sulfamethoxazole $(n=1)$, and compound of sulfonamides $(n=1)$. ${ }^{\mathrm{f}}$ Others in antibiotics including azithromycin $(n=1)$, clarithromycin $(n=1)$, lincomycin $(n=2)$, doxycyclin $(n=1)$, and vancomycin $(n=1)$. ${ }^{\mathrm{g}}$ Unspecified as not available, unspecified in contained group. ${ }^{\mathrm{h}}$ Multiple drugs in antibiotics as concomitant use of multiple antibiotics. ${ }^{\mathrm{i}}$ Others in anticonvulsants including oxcarbazepine $(n=2)$, compound of phenobarbital and scopolamine $(n=1)$, and phenytoin $(n=1) .{ }^{j}$ Chinese patent medicines including extract of Andrographis paniculata $(n=1)$, bupleurum granule (containing bupleurum, Pinellia ternata with ginger, radix scutellariae, Codonopsis pilosula, etc.) ( $n=1)$, cough granule (containing loquat, opium poppy husk, stemona, mulberry bark, swallowwort rhizome, etc.) $(n=1)$, Gutong capsule (containing ginseng, resina draconis, scorpion, bungarus minimus, etc.) $(n=1)$, Honghua tablet (containing Emilia sonchifolia, Hedyotis diffusa, caulis spatholobi, etc.) $(n=1)$, sleeping capsule (containing lilium, Acanthopanax senticosus, caulis polygoni multiflori, Albizia julibrissin durazz, mother-of-pearl, etc.) $(n=1)$, and unspecified $(n=3)$. ${ }^{\mathrm{k}}$ Industrial chemicals including acetochlor $(n=1)$, naphthalenedisulfonic acid dimethyl ester $(n=1)$, and trichloroethylene $(n=1)$. ${ }^{1}$ NSAIDs including analgin $(n=1)$, diclofenac sodium eye drops or tablets $(n=3)$, compound of paracetamol, aspirin and caffeine $(n=1)$, compound of paracetamol, aminophenazone, caffeine, and chlorphenamine maleate $(n=1)$, compound of paracetamol, aminopyrine, phenacetin, caffeine, and phenobarbital $(n=1)$, and ibuprofen $(n=1)$. ${ }^{\mathrm{m}}$ Multiple drugs as different classification of drugs in concomitant use, including NSAID concomitant with antibiotic and anticonvulsant $(n=4)$, Chinese patent drug concomitant with antibiotic $(n=1)$, Chinese patent drug concomitant with unknown cold medicine $(n=2)$, and concomitant with multiple unknown cold medicine $(n=3)$. ${ }^{\mathrm{n}}$ Others including calcium dobesilate $(n=1)$, methazolamide $(n=8)$, multiple antifungals (itraconazole and voriconazole) $(n=1)$, multiple antidepressant (amitriptyline and estazolam) $(n=1)$, and multiple antituberculosis drugs $(n=1) .{ }^{\circ}$ Nondrugs as absence of medication using history before onset.

years, all patients were older than 40 years, ranging from 51 to 94 . Among 9 deceased patients, 4 patients received systemic steroids in combination with IVIG, 3 in the early stage and 1 in the late stage, and 5 patients received systemic steroids only.

3.4. Treatment with Combination of Steroid and IVIG versus Steroid Alone. There were 90 (54.2\%) patients of SJS/TEN who received systemic steroids alone and 76 (45.8\%) patients who had IVIG in combination with systemic steroids. Combination treatment was more commonly used in TEN patients than in SJS patients (64.9\% versus 20.8\%) (Odds ratio: $7.024 ; P<0.001$ ) (Table 1 ). In 76 patients who received systemic steroids with IVIG in combination, 61 (80.3\%) of them were TEN, and the mortality rate of TEN cases receiving combination treatment was 6.6\% (4/61). In 90 patients who received systemic steroids alone, 33 patients $(36.7 \%)$ were TEN, and $12.1 \%$ (4/33) of these TEN cases underwent steroid alone deceased. On the other hand, 57 patients with SJS and SJS-TEN received systemic steroids alone and only $1(1.8 \%)$ died. There were 15 SJS and SJS-TEN patients who received combination treatment, and all survived. Mortality rate between using IVIG and steroid in combination or steroid alone had no statistical significance (Table 6). 
TABLE 3: Comparison of the common drug causality between northern and southern China.

\begin{tabular}{lccc}
\hline & $\begin{array}{c}\text { Northern China, Southern China, } \\
n(\%) \\
(n=46)\end{array}$ & $\begin{array}{c}\text { Total, } \\
n(\%)\end{array}$ \\
& $14(30.4)$ & $35(29.2)$ & $49(29.5)$ \\
& $3(6.5)$ & $9(7.5)$ & $12(7.2)$ \\
\hline Antibiotics & $1(2.2)$ & $6(5.0)$ & $7(4.2)$ \\
$\quad$ Penicillins & $2(4.3)$ & $4(3.3)$ & $6(3.6)$ \\
Cephalosporins & $8(17.4)$ & $16(13.3)$ & $24(14.5)$ \\
Quinolones & $13(28.3)$ & $27(22.5)$ & $40(24.1)$ \\
$\quad$ Others & $9(19.6)$ & $20(16.7)$ & $29(17.5)$ \\
Anticonvulsants & $2(4.3)$ & $5(4.2)$ & $7(4.2)$ \\
$\quad$ Carbamazepine & $2(4.3)$ & $2(1.7)$ & $4(2.4)$ \\
$\quad$ Lamotrigine & $1(2.2)$ & $18(15.0)$ & $19(11.4)$ \\
$\quad$ Others & $2(4.3)$ & $14(11.7)$ & $16(9.6)$ \\
Nondrug & $6(13.0)$ & $4(3.3)$ & $10(6.0)$ \\
Allopurinol & $2(4.3)$ & $7(5.8)$ & $9(5.4)$ \\
Multiple drugs & $4(8.7)$ & $4(3.3)$ & $8(4.8)$ \\
Herbal medication & $4(8.7)$ & $11(9.2)$ & $15(9.0)$ \\
NSAIDs &
\end{tabular}

NSAIDs: nonsteroidal anti-inflammatory drugs.

\section{Discussion}

In this study, we enrolled a total 166 Han Chinese patients diagnosed with SJS, SJS-TEN overlap, and TEN from a tertiary medical center and Chinese literatures during 2006 to 2016. We evaluated underlying condition, causation, treatment, and clinical outcome. Mean age of SJS/TEN was 43.5 years, with little difference between SJS or SJS-TEN overlap and TEN. There was a male predominance in SJS or SJSTEN overlap (male-to-female ratio 1.77:1) and TEN (maleto-female ratio $1.35: 1$ ). This observation was opposite to what Mohammed et al. found in Egypt and different from an earlier study which showed equally affected by male and female $[42,43]$.

There were $88.6 \%$ of SJS/TEN patients had drug relationship, and the major contribution was antibiotics, followed by anticonvulsants and allopurinol. The difference between the antibiotics and anticonvulsants was small. This result was similar to the comparison of Malaysia and Singapore in a review of Southeast Asia [41], only different in sequence of antibiotics and anticonvulsants, whereas Huang et al. found anticonvulsants as the most common drug which caused SJS/TEN in China, followed by allopurinol, antipyretics/ analgesics, and cephalosporins [44]. Similarly, Li and $\mathrm{Ma}$ reported anticonvulsants and antibiotics to be the most common single drug in SJS and traditional Chinese medicines in TEN [45]. It is known that allopurinol, aromatic anticonvulsants, sulfonamide antibiotics, oxicam NSAIDs, and nevirapine have higher risk to induced SCARs [46]. Nevertheless, there were only some sulphonamides and none oxicam type of NSAIDs induced SJS/TEN in this study. This may due to prescribing habits of antibiotics in China and Taiwan, causing more penicillins and cephalosporins than the others [47-50]. Similarly, oxicam type of NSAIDs is less commonly seen in Chinese literatures of case series [48, 49]. Allopurinol was found to be a less common causality to induce SJS/TEN in this study, especially in northern China. From previous reports, $H L A-B^{*} 58: 01$ was found positive in $93.3-100 \%$ of patients with allopurinol-induced SCARs whether in northern or southern China [51-54]. Moreover, the prevalence of carrying the risk $H L A-B^{*} 58: 01$ allele was 0.0515-0.085 in China [55]. The discrepancy of the percentages between this study and literature needs further investigation. Chinese patent medicines were unique causative drugs to induce SJS/ TEN in the Asian region [43, 56-59]. In our study, 5.4\% of the SJS/TEN cases were related to Chinese patent medicine. Previously, Singapore was also reported to have more herbal medicine-induced SJS/TEN cases [41]. However, there are possibilities of adulteration with Western medicine in the component of Chinese patent medicine [60-62], which makes it hard to identify the exact causality and may cause bias. Patients also tend to received multiple drugs, including compound preparations of Western medicine or even antipyretic and analgetic in Chinese patent medicine [45]. Both of these would increase the possibility of adverse drug reaction and enhance difficulty of identifying offending drug.

In our study, $19 \%$ of patients did not have definite or possible relationship with drug according to ALDEN scoring system. The cause may be infection or idiopathic, and unfortunately there were no validation via further examinations. The annual incidence of SJS/TEN in the HIV-positive population is approximately 1000-fold higher than in the general population [63], and 4 patients with suspected causative drugs were HIV positive in our study. Infections are possible causations besides drugs. Reactivations of human herpesvirus 6 (HHV6) and cytomegalovirus were found in SJS/TEN $[64,65]$. A case has been reported of a teenage boy diagnosed with SJS and primary Epstein-Barr virus infection without any attributing medication [66]. In addition, Mycoplasma pneumoniae infection may also be an additional cause of SJS. Watkins et al. and Olson et al. have reported Mycoplasma pneumoniae infection outbreak associated with SJS in children $[67,68]$. Although there were some reports with malignancy-related SJS [69, 70], none of our non-druginduced-SJS/TEN patients were found to have malignancy.

Withdrawal of offending drugs or treatment of causative infection, timely supportive treatment, immunomodulation, and management of complications and consequences are the most common suggested treatments [71]. In this study, all of the patients received systemic corticosteroid. Despite systemic corticosteroids remain a controversial treatment for SJS/TEN, it is the most commonly used medication across Asia [72-75].

Massive keratinocyte apoptosis induced by the intercellular death receptor Fas and Fas ligand is now considered to be the pathogenesis of SJS/TEN [76], yet IVIG inhibits keratinocyte apoptosis by inhibiting the FAS receptor [77]. IVIG was prescribed as an additional management in $45.8 \%$ of our patients, whether at the early or late stage of SJS/TEN, especially with much higher percentage in TEN (80.3\%) compared to SJS or SJS-TEN overlap (19.7\%). Apparently IVIG is a common option of treating SJS/TEN in China, especially in TEN for their extensive skin lesion involvement, and is 
TABLE 4: The comparison of the common drug causality from cases in China with other populations in Southeast Asia*.

\begin{tabular}{|c|c|c|c|c|c|}
\hline Culprit drug & China $(n=166)$ & Malaysia $(n=162)$ & Singapore $(n=159)$ & Thailand $(n=60)$ & Philippines $(n=28)$ \\
\hline Antibiotics & $49(29.5)$ & $45(27.8)$ & $46(28.9)$ & $40(66.7)$ & $5(17.9)$ \\
\hline Penicillins & $12(7.2)$ & $14(8.6)$ & $19(11.9)$ & $19(31.7)$ & $1(3.6)$ \\
\hline Sulfonamide & $4(2.4)$ & $28(17.3)$ & $11(6.9)$ & $9(15.0)$ & $2(7.1)$ \\
\hline Others & $33(19.9)$ & $3(1.9)$ & $16(10.1)$ & $12(20.0)$ & $2(7.1)$ \\
\hline Anticonvulsants & $40(24.1)$ & $54(33.3)$ & $47(29.6)$ & $9(15.0)$ & $12(42.9)$ \\
\hline Carbamazepine & $29(17.5)$ & $34(21.0)$ & $29(18.2)$ & $4(6.7)$ & $4(14.3)$ \\
\hline Lamotrigine & $7(4.2)$ & $7(4.3)$ & $2(1.3)$ & $0(0)$ & $0(0)$ \\
\hline Phenytoin & $1(0.6)$ & $13(8.0)$ & $14(8.8)$ & $4(6.7)$ & $5(17.9)$ \\
\hline Allopurinol & $16(9.6)$ & $33(20.4)$ & $23(14.5)$ & $1(1.7)$ & $6(21.4)$ \\
\hline NSAIDs & $8(4.8)$ & $10(6.2)$ & $14(8.8)$ & $4(6.7)$ & $3(10.7)$ \\
\hline Herbal medications & $9(5.4)$ & $4(2.5)$ & $12(7.5)$ & $0(0)$ & $1(3.6)$ \\
\hline
\end{tabular}

${ }^{*}$ We compared the common drug causality from cases in China with other populations in Southeast Asia according to the previous literature report (41).

TABLE 5: Information of the deceased patients with SJS/TEN in this study ( $n=\mathrm{XXX})$.

\begin{tabular}{|c|c|c|c|c|c|c|}
\hline Phenotype & Sex & Age, $y$ & Underlying disease & SCORTEN & Culprit drugs & Treatment \\
\hline SJS & $\mathrm{M}$ & 51 & Chronic renal failure, diabetes & 4 & Allopurinol & Systemic steroids \\
\hline TEN & $\mathrm{M}$ & 70 & Nil & 6 & Antibiotics & Systemic steroids \\
\hline TEN & $\mathrm{F}$ & 58 & Aneurysm, subarachnoid hemorrhage & NA & Antibiotics & Systemic steroids \\
\hline TEN & $\mathrm{F}$ & 67 & $\begin{array}{l}\text { Rheumatic heart disease, mitral } \\
\text { insufficiency }\end{array}$ & NA & $\begin{array}{l}\text { Antibiotics and compound } \\
\text { with aminopyrine, phenacetin, } \\
\text { caffeine, phenobarbital }\end{array}$ & $\begin{array}{l}\text { Systemic steroids with } \\
\text { IVIG use in the late } \\
\text { stage }\end{array}$ \\
\hline TEN & $\mathrm{F}$ & 71 & $\begin{array}{l}\text { Coronary heart disease, hypertension, } \\
\text { diabetes, diabetic nephropathy }\end{array}$ & 4 & Calcium dobesilate & $\begin{array}{l}\text { Systemic steroids with } \\
\text { IVIG use in the early } \\
\text { stage }\end{array}$ \\
\hline TEN & M & 62 & Hypertension, diabetes & NA & Antibiotics & $\begin{array}{l}\text { Systemic steroids with } \\
\text { IVIG use in the early } \\
\text { stage }\end{array}$ \\
\hline TEN & M & 94 & $\begin{array}{l}\text { Coronary heart disease, cardiac } \\
\text { insufficiency, hypertension, diabetes, } \\
\text { interstitial lung disease }\end{array}$ & NA & Antibiotics & $\begin{array}{l}\text { Systemic steroids with } \\
\text { IVIG use in the early } \\
\text { stage }\end{array}$ \\
\hline TEN & M & 62 & $\begin{array}{l}\text { Hypertension, diabetes, chronic renal } \\
\text { failure, hyperuricemia }\end{array}$ & NA & Allopurinol & Systemic steroids \\
\hline TEN & $\mathrm{M}$ & 3 & Nil & 2 & Antibiotics & Systemic steroids \\
\hline
\end{tabular}

IVIG use in the early stage $\leq 7$ days of onset; IVIG use in the late stage $\geq 7$ days of onset. NA: not available.

TABLE 6: A comparison of mortality rate between combination treatment of steroid with IVIG versus steroid alone.

\begin{tabular}{|c|c|c|c|c|}
\hline Mortality & Steroids with IVIG $(n=76)$ & Steroids alone $(n=90)$ & Odds ratio $(95 \% \mathrm{CI})$ & $P$ values \\
\hline TEN, $n(\%)$ & $4 / 61(6.6)$ & $4 / 33(12.1)$ & $0.509(0.119-2.183)$ & 0.445 \\
\hline SJS and SJS/TEN, $n(\%)$ & $0 / 15(0.0)$ & $1 / 57(1.8)$ & - & 1.000 \\
\hline Total cases, $n(\%)$ & $4 / 76(5.3)$ & $5 / 90(5.6)$ & $0.944(0.244-3.650)$ & 1.000 \\
\hline
\end{tabular}

usually in combination of systemic steroids instead of using alone. A score-based comparison study of clinical outcomes found that corticosteroid therapy combined with IVIG may lead to lower mortality when compared to corticosteroid alone [78]. However, several studies have shown limited success of IVIG in the clinical settings [79-82]. In our study, mortality rate in patients with TEN who received systemic steroids with IVIG comparing to those who received systemic steroids alone was $6.6 \%$ and $12.1 \%$. However, this difference of mortality rate was not statistically significant. Application of intravenous immunoglobulins or systemic corticosteroids also did not improve the outcome of SJS and TEN in a study in Singapore [83]. Similarly, Lee et al. [84] demonstrated that the use of IVIG does not yield survival benefits in SJS/TEN overlap and TEN, even when corrected for IVIG dosages. Until now, the usage of IVIG in the treatment of SJS/TEN 
is still controversial. Recent studies have shown that immunosuppressive treatment with tumor necrosis factor-alpha (TNF- $\alpha$ ) inhibitors may be helpful [85] and cyclosporin A is also safe and may contribute to rapid reepithelialization in patients with SJS/TEN [86-88]. The efficacy of using cyclosporin in treating SJS/TEN has recently validated with the decreased mortality rate both in adults and children [89-92].

There are several limitations in this study. First, we enrolled case reports only with careful checkup to prevent overlapping cases. However, ruling out the articles with case series also led to underestimation of SJS/TEN patients. Second, the mortality rate in our study is lower than international literatures which ranged from $10 \%$ to $70 \%[93,94]$. The possibility of lower mortality in this study may be due to underreported deceased cases of SJS/TEN from the Chinese literatures. In addition, the underlying severity of SJS/TEN in our study is unknown due to the lack of complete data of SCORTEN factors; hence, the efficacy of treatment needs to be further elucidated.

\section{Conclusion}

SJS/TEN is life-threatening drug adverse reaction, with higher prevalence rate in Asian than in Western populations in literature review. The most common offending drugs in our study are antibiotics, anticonvulsants, and allopurinol. IVIG in combination with systemic steroids is a common option especially for TEN in China. There was no significant difference in the mortality rate of TEN patients with or without IVIG adjuvant treatment.

\section{Conflicts of Interest}

The authors declare that there is no conflict of interest regarding the publication of this paper.

\section{Acknowledgments}

The authors thank Chun-Bing Chen (Department of Dermatology, Drug Hypersensitivity Clinical and Research Center, Chang Gung Memorial Hospital, Taipei, Linkou, and Keelung, Chang Gung University, Taoyuan, Taiwan) for assisting this article.

\section{References}

[1] J. C. Roujeau, "Immune mechanisms in drug allergy," Allergology International, vol. 55, no. 1, pp. 27-33, 2006.

[2] S. C. Su, M. Mockenhaupt, P. Wolkenstein et al., "Interleukin15 is associated with severity and mortality in Stevens-Johnson syndrome/toxic epidermal necrolysis," Journal of Investigative Dermatology, vol. 137, no. 5, pp. 1065-1073, 2017.

[3] W. H. Chung, S. I. Hung, J. Y. Yang et al., "Granulysin is a key mediator for disseminated keratinocyte death in StevensJohnson syndrome and toxic epidermal necrolysis," Nature Medicine, vol. 14, no. 12, pp. 1343-1350, 2008.

[4] S. J. Posadas, A. Padial, M. J. Torres et al., "Delayed reactions to drugs show levels of perforin, granzyme B, and Fas-L to be related to disease severity," The Journal of Allergy and Clinical Immunology, vol. 109, no. 1, pp. 155-161, 2002.

[5] W. H. Chung, C. W. Wang, and R. L. Dao, "Severe cutaneous adverse drug reactions," The Journal of Dermatology, vol. 43, no. 7, pp. 758-766, 2016.

[6] J. C. Roujeau and R. S. Stern, "Severe adverse cutaneous reactions to drugs," The New England Journal of Medicine, vol. 331, no. 19, pp. 1272-1285, 1994.

[7] S. Bastuji-Garin, N. Fouchard, M. Bertocchi, J. C. Roujeau, J. Revuz, and P. Wolkenstein, "SCORTEN: a severity-ofillness score for toxic epidermal necrolysis," Journal of Investigative Dermatology, vol. 115, no. 2, pp. 149-153, 2000.

[8] H. L. Chan, R. S. Stern, K. A. Arndt et al., "The incidence of erythema multiforme, Stevens-Johnson syndrome, and toxic epidermal necrolysis. A population-based study with particular reference to reactions caused by drugs among outpatients," Archives of Dermatology, vol. 126, no. 1, pp. 43-47, 1990.

[9] N. Frey, J. Jossi, M. Bodmer et al., "The epidemiology of Stevens-Johnson syndrome and toxic epidermal necrolysis in the UK," Journal of Investigative Dermatology, vol. 137, no. 6, pp. 1240-1247, 2017.

[10] S. Y. Liu, T. T. Liu, Y. J. Yu, and R. Q. Wang, "A case of toxic epidermal necrolysis," China Journal of Leprosy and Skin Diseases, vol. 25, no. 6, p. 456, 2009.

[11] P. Xia, W. Y. Wu, J. Ren, X. M. Hou, and Z. Z. Zheng, “Toxic epidermal necrolysis: a case report," Journal of Clinical Dermatology, vol. 38, no. 12, pp. 778-779, 2009.

[12] Y. X. Li, Q. Fu, X. C. Zhang, and L. X. Du, “Toxic epidermal necrolysis: a case report," The Chinese Journal of Dermatovenereology, vol. 24, no. 4, p. 388, 2010.

[13] J. B. Du, Y. Q. Chu, S. Guo, X. L. Qi, and C. Zhao, "Toxic epidermal necrolysis associated with imipenem/cilastatin sodium," Adverse Drug Reactions Journal, vol. 12, no. 6, pp. 431-433, 2010.

[14] X. F. Fang, X. X. Zhang, and J. W. Li, "A case of toxic epidermal necrolysis caused by exposure to acetochlor," China Journal of Leprosy and Skin Diseases, vol. 27, no. 4, pp. 273-274, 2011.

[15] J. J. Liu, S. C. Lv, H. M. Yang, B. Li, J. L. Liu, and T. B. Xia, “A case of toxic epidermal necrolysis induced by carbamazepine subcutaeous embedded," Journal of Practical Dermatology, vol. 5, no. 6, pp. 372-373, 2012.

[16] F. Yang and F. Liu, "Fatal of severe aneurysm complicated with toxic epidermal necrolysis," West China Medical Journal, vol. 27, no. 8, pp. 1166-1167, 2012.

[17] M. Q. Sun, L. Tong, and Y. Liu, "A case report of toxic epidermal necrolysis," The Chinese Journal of Dermatovenereology, vol. 27, no. 12, pp. 1308-1309, 2013.

[18] K. Yu, Y. Y. Wang, L. Chang et al., "A case of Steven-Johnson syndrome caused by diclofenac sodium eye drops," Chinese Journal of Dermatovenereology, vol. 28, no. 6, pp. 611-612, 2014.

[19] H. Xu, X. F. Chen, W. G. Wang, and W. H. Ge, "A fatal of toxic epidermal necrolysis caused by compound of analgesic tablets," Chinese Journal of Difficult and Complicated Cases, vol. 13, no. 11, pp. 1195-1196, 2014.

[20] X. H. Tang, H. Zhou, M. H. Zhong, G. L. Cao, and Q. Gao, "Blindness caused by Stevens-Johnson syndrome in children: a case report," Journal of Diagnosis and Therapy on Dermato-venereology, vol. 22, no. 3, pp. 247-249, 2015.

[21] R. X. Ren, L. Jia, and H. Y. Zheng, "Toxic epidermal necrolysis in $H L A-B^{*} 1502$ gene carrier induced by carbamazepine: a case 
report," Journal of Clinical Dermatology, vol. 44, no. 10, pp. 638-639, 2015.

[22] Y. Qiang, L. H. Chen, Y. H. Zhang, Y. Shen, X. Q. Zhao, and M. Pan, "Toxic epidermal necrolysis in a patient with adultonset still disease and literature review," Chinese Journal of Dermatovenereology, vol. 29, no. 9, pp. 943-945, 2015.

[23] J. J. Liu, Y. Jiang, J. Lv, and G. F. Yan, "A case of calcium dobesilate-induced toxic epidermal necrolysis," Chinese Journal of Dermatovenereology, vol. 29, no. 6, pp. 615-616, 2015.

[24] H. Bai, W. W. Tong, X. Q. Wei, and J. Guo, "Treatment analysis of a fatal with severe acute pancreatitis and toxic epidermal necrolysis," Chinese Journal of Hospital Pharmacy, vol. 35, no. 8, pp. 763-764, 2015.

[25] H. Zhang and Y. Zhong, "One case of drug-induced bullosa epidermolysis caused by amoxicillin-sulbactam," Chinese Journal of New Drugs and Clinical Remedies, vol. 34, no. 9, pp. 689691, 2015.

[26] C. Y. Wei and T. Xu, "A fatal of toxic epidermal necrolysis induced by allopurinol," Chinese Journal of Pharmacoepidemiology, vol. 24, no. 3, pp. 189-190, 2015.

[27] T. Zhang, R. F. Shi, and J. Zheng, "A case of toxic epidermal necrolysis complicated with HIV infection," Chinese Journal of Dermatology, vol. 41, no. 5, p. 345, 2008.

[28] J. P. Chu and Y. Wang, "Carbamazepine-induced toxic epidermal necrolysis: a case report," Shaanxi Medical Journal, vol. 40, no. 5, p. 640, 2011.

[29] R. J. Jin, X. Y. Zhan, J. X. Jiang, and L. P. Sun, "A case of methazolamide-induced Stevens-Johnson syndrome," Chinese Journal of Dermatovenereology, vol. 26, no. 4, pp. 363-364, 2012.

[30] X. L. He, Z. S. Liu, G. F. Wu et al., "Carbamazepine-induced Stevens-Johnson syndrome with negative $H L A-B^{*} 1502$ : case report and literature review," Journal of Clinical Pediatrics, vol. 30, no. 11, pp. 1006-1010, 2012.

[31] H. Wei, B. Wang, and F. Liu, "A case report: toxic epidermal necrolysis caused by allopurinol," Chinese Medical Record, vol. 14, no. 8, pp. 36-38, 2013.

[32] C. Wu, H. Z. Jin, K. Fang, and L. Li, “A case of Stevens-Johnson syndrome presented as chickenpox-like lesions," Journal of Clinical Dermatology, vol. 43, no. 3, pp. 159-161, 2014.

[33] W. H. Liu, Y. N. Zhang, and Q. Zhang, "Methazolamideinduced Stevens-Johnson syndrome before and after glaucoma surgery," Chinese Journal of Ocular Trauma and Occupational Eye Disease, vol. 36, no. 11, pp. 850-852, 2014.

[34] J. Li, J. J. Tao, J. Lu, and Y. D. Zhao, "A case of SJS/TEN overlap induced by oral methazolamide," Chinese Journal of Ophthalmology, vol. 51, no. 12, pp. 934-935, 2015.

[35] J. M. Jiang and Z. W. Zhang, "A case of carbamazepineinduced Stevens-Johnson syndrome," Evaluation and Analysis of Drug-Use in Hospitals of China, vol. 15, no. 9, article 1280, 2015.

[36] Y. L. Li and J. Liu, "Allopurinol-induced Stevens-Johnson syndrome in a HLA-B*5801 allele gene carrier," Evaluation and Analysis of Drug-Use in Hospitals of China, vol. 15, no. 11, pp. 1567-1568, 2015.

[37] Y. H. Xu, Y. Su, J. Zhao, Y. J. Du, and Q. Sun, "Methazolamideinduced toxic epidermal necrolysis in a patient with $H L A^{*}$ B5901 allele," Chinese Journal of Dermatology, vol. 48, no. 2, pp. 131-133, 2015.

[38] W. H. Chung, W. C. Chang, Y. S. Lee et al., "Genetic variants associated with phenytoin-related severe cutaneous adverse reactions," The Journal of the American Medical Association, vol. 312, no. 5, pp. 525-534, 2014.

[39] C. Y. Ng, Y. T. Yeh, C. W. Wang et al., "Impact of the HLA$B\left(^{*}\right) 58: 01$ allele and renal impairment on allopurinol-induced cutaneous adverse reactions," The Journal of Investigative Dermatology, vol. 136, no. 7, pp. 1373-1381, 2016.

[40] C. B. Chen, Y. H. Hsiao, T. Wu et al., "Risk and association of HLA with oxcarbazepine-induced cutaneous adverse reactions in Asians," Neurology, vol. 88, no. 1, pp. 78-86, 2017.

[41] H. Y. Lee, W. Martanto, and T. Thirumoorthy, "Epidemiology of Stevens-Johnson syndrome and toxic epidermal necrolysis in Southeast Asia," Dermatologica Sinica, vol. 31, no. 4, pp. 217-220, 2013.

[42] A. E. Mohammed, E. E. Reham, and A. E. Wafaa, "A clinicoetiological analysis of patients with Stevens-Johnson syndrome and toxic epidermal necrolysis treated at Sohag University Hospital, Egypt," Journal of the Egyptian Women's Dermatologic Society, vol. 14, no. 1, pp. 37-44, 2017.

[43] S. K. Tan and Y. K. Tay, "Profile and pattern of StevensJohnson syndrome and toxic epidermal necrolysis in a general hospital in Singapore: treatment outcomes," Acta DermatoVenereologica, vol. 92, no. 1, pp. 62-66, 2012.

[44] H. Y. Huang, X. Q. Luo, L. S. Chan, Z. H. Cao, X. F. Sun, and J. H. Xu, "Cutaneous adverse drug reactions in a hospitalbased Chinese population," Clinical and Experimental Dermatology, vol. 36, no. 2, pp. 135-141, 2011.

[45] L. F. Li and C. Ma, "Epidemiological study of severe cutaneous adverse drug reactions in a city district of China," Clinical and Experimental Dermatology, vol. 31, no. 5, pp. 642-647, 2006.

[46] S. C. Su, S. I. Huang, W. L. Fan, R. L. Dao, and W. H. Chung, "Severe cutaneous adverse reactions: the pharmacogenomics from research to clinical implementation," International Journal of Molecular Sciences, vol. 17, no. 11, article E1890, 2016.

[47] J. Sun, J. Liu, Q. L. Gong et al., "Stevens-Johnson syndrome and toxic epidermal necrolysis: a multi-aspect comparative 7year study from the People's Republic of China," Drug Design Development and Therapy, vol. 8, pp. 2539-2547, 2014.

[48] C. Y. Gong, B. X. Wang, and M. W. Yu, "Clinical analysis of 58 cases of severe drug eruption," Chinese Journal of Dermatovenereology, vol. 29, no. 1, pp. 39-41, 2015.

[49] S. Wang, J. H. Zhao, Q. M. Sun, J. J. Qiao, and H. Fang, "Clinical analysis of 55 cases of severe drug eruption," Chinese Journal of Dermatovenereology, vol. 30, no. 12, pp. 1241-1243, 2016.

[50] Y. F. Lin, C. H. Yang, S. Hu et al., "Severe cutaneous adverse reactions related to systemic antibiotics," Clinical Infectious Diseases, vol. 58, no. 10, pp. 1377-1385, 2014.

[51] Z. H. Cao, Z. Y. Wei, Q. Y. Zhu et al., " $H L A-B^{*}$ 58:01 allele is associated with augmented risk for both mild and severe cutaneous adverse reactions induced by allopurinol in Han Chinese," Pharmacogenomics, vol. 13, no. 10, pp. 1193-1201, 2012.

[52] Z. Y. Deng, J. Yang, and W. L. Yang, "Detection of the HLA-B* 5801 allele in Han Chinese with allopurinol-induced severe drug eruption," Journal of Diagnosis and Therapy on Dermato-venereology, vol. 20, no. 6, pp. 379-382, 2013.

[53] L. Cheng, Y. Xiong, C. Z. Qin et al., " $H L A-B^{*}$ 58:01 is strongly associated with allopurinol-induced severe cutaneous adverse reactions in Han Chinese patients: a multicentre retrospective case-control clinical study," British Journal of Dermatology, vol. 173, no. 2, pp. 555-558, 2015. 
[54] Z. Y. Deng, J. Yang, and W. L. Yang, "Relationship between $H L A-B^{*} 5801$ allele and allopurinol-induced severe drug eruption in Han Chinese population from Zhoukou," Journal of Clinical Dermatology, vol. 46, no. 1, pp. 28-29, 2017.

[55] Y. Zhang, X. M. Nie, Y. L. Zhuang, Y. H. Song, Y. Liu, and C. F. Zhu, "HLA-A, B and DRB1 polymorphism at high-resolution in Han population from southern area of Shandong province in China," Journal of Experimental Hematology, vol. 19, no. 6, pp. 1482-1488, 2011.

[56] S. Batra, "Serious cutaneous adverse reactions to traditional Chinese medicines," Singapore Medical Journal, vol. 47, no. 7, p. 647, 2006.

[57] A. D. Sanmarkan, T. Sori, D. M. Thappa, and T. J. Jaisankar, "Retrospective analysis of Stevens-Johnson syndrome and toxic epidermal necrolysis over a period of 10 years," Indian Journal of Dermatology, vol. 56, no. 1, pp. 25-29, 2011.

[58] S. Wechwithan, W. Suwankesawong, V. Sornsrivichai, E. B. McNeil, C. Jiraphongsa, and V. Chongsuvivatwong, "Signal detection for Thai traditional medicine: examination of national pharmacovigilance data using reporting odds ratio and reported population attributable risk," Regulatory Toxicology and Pharmacology, vol. 70, no. 1, pp. 407-412, 2014.

[59] Y. L. Lim and T. Thirumoorthy, "Serious cutaneous adverse reactions to traditional Chinese medicines," Singapore Medical Journal, vol. 46, no. 12, pp. 714-717, 2005.

[60] S. J. Lai, S. R. Binder, H. Essin, and K. C. Wen, "Identification of Western medicines as adulterants in Chinese herbal medicine using a broad-spectrum drug screening HPLC system," Journal of Liquid Chromatography, vol. 18, no. 14, pp. 28612875, 2006.

[61] G. M. Miller and R. Stripp, "A study of western pharmaceuticals contained within samples of Chinese herbal/patent medicines collected from New York City's Chinatown," Legal Medicine, vol. 9, no. 5, pp. 258-264, 2007.

[62] L. C. Ma, Z. Hong, Z. Jiao, X. J. Shi, and M. K. Zhong, "Indentification of 53 species antiepileptic Chinese traditional medicine," Chinese Journal of Clinical Neurosciences, vol. 19, no. 2, pp. 146-149, 2011.

[63] J. C. Roujeau, J. P. Kelly, L. Naldi et al., "Medication use and the risk of Stevens-Johnson syndrome or toxic epidermal necrolysis," The New England Journal of Medicine, vol. 333, no. 24, pp. 1600-1608, 1995.

[64] Y. Teraki, H. Murota, and S. Izaki, "Toxic epidermal necrolysis due to zonisamide associated with reactivation of human herpesvirus 6," Archives of Dermatology, vol. 144, no. 2, pp. 232-235, 2008.

[65] T. Ishida, Y. Kano, Y. Mizukawa, and T. Shiohara, "The dynamics of herpesvirus reactivations during and after severe drug eruptions: their relation to the clinical phenotype and therapeutic outcome," Allergy, vol. 69, no. 6, pp. 798-805, 2014.

[66] F. Brunet-Possenti, M. Steff, E. Marinho, B. Crickx, and V. Descamps, "Stevens-Johnson syndrome concurrent with primary Epstein-Barr virus infection," Annales de Dermatologie et de Vénéréologie, vol. 140, no. 2, pp. 112-115, 2013.

[67] L. K. Watkins, D. Olson, M. H. Diaz et al., "Epidemiology and molecular characteristics of Mycoplasma pneumoniae during an outbreak of $M$. pneumoniae-associated Stevens-Johnson syndrome," The Pediatric Infectious Disease Journal, vol. 36, no. 6, pp. 564-571, 2017.
[68] D. Olson, L. K. Watkins, A. Demirjian et al., "Outbreak of Mycoplasma pneumoniae-associated Stevens-Johnson syndrome," Pediatrics, vol. 136, no. 2, pp. e386-e394, 2015.

[69] J. Z. Yetiv, J. R. Bianchine, and J. A. Owen Jr., "Etiologic factors of the Stevens-Johnson syndrome," Southern Medical Journal, vol. 73, no. 5, pp. 599-602, 1980.

[70] M. Mockenhaupt, "The current understanding of StevensJohnson syndrome and toxic epidermal necrolysis," Expert Review of Clinical Immunology, vol. 7, no. 6, pp. 803-815, 2011.

[71] T. Harr and L. E. French, "Toxic epidermal necrolysis and Stevens-Johnson syndrome," Orphanet Journal of Rare Diseases, vol. 5, no. 1, p. 39, 2010.

[72] Y. Araki, C. Sotozono, T. Inatomi et al., "Successful treatment of Stevens-Johnson syndrome with steroid pulse therapy at disease onset," American Journal of Ophthalmology, vol. 147, no. 6, pp. 1004-1011.e1, 2009.

[73] H. I. Kim, S. W. Kim, G. Y. Park et al., "Causes and treatment outcomes of Stevens-Johnson syndrome and toxic epidermal necrolysis in 82 adult patients," Korean Journal of Internal Medicine, vol. 27, no. 2, pp. 203-210, 2012.

[74] K. Hirahara, Y. Kano, Y. Sato et al., "Methylprednisolone pulse therapy for Stevens-Johnson syndrome/toxic epidermal necrolysis: clinical evaluation and analysis of biomarkers," Journal of the American Academy of Dermatology, vol. 69, no. 3, pp. 496498, 2013.

[75] P. Su and C. W. Aw, "Severe cutaneous adverse reactions in a local hospital setting: a 5-year retrospective study," International Journal of Dermatology, vol. 53, no. 11, pp. 1339-1345, 2014.

[76] M. Ueta, C. Sotozono, T. Inatomi, K. Kojima, J. Hamuro, and S. Kinoshita, "Association of Fas Ligand gene polymorphism with Stevens-Johnson syndrome," British Journal of Ophthalmology, vol. 92, no. 7, pp. 989-991, 2008.

[77] Y. C. Huang, Y. C. Li, and T. J. Chen, "The efficacy of intravenous immunoglobulin for the treatment of toxic epidermal necrolysis: a systematic review and meta-analysis," British Journal of Dermatology, vol. 167, no. 2, pp. 424-432, 2012.

[78] Q. Y. Zhu, L. Ma, X. Q. Luo, and H. Y. Huang, "Toxic epidermal necrolysis: performance of SCORTEN and the scorebased comparison of the efficacy of corticosteroid therapy and intravenous immunoglobulin combined therapy in China," Journal of Burn Care \& Research, vol. 33, no. 6, pp. e295-e308, 2012.

[79] J. Lalosevic, M. Nikolic, M. Gajic-Veljic, D. Skiljevic, and L. Medenica, "Stevens-Johnson syndrome and toxic epidermal necrolysis: a 20-year single-center experience," International Journal of Dermatology, vol. 54, no. 8, pp. 978-984, 2015.

[80] N. Bachot, J. Revuz, and J. C. Roujeau, "Intravenous immunoglobulin treatment for Stevens-Johnson syndrome and toxic epidermal necrolysis: a prospective noncomparative study showing no benefit on mortality or progression," Archives of Dermatology, vol. 139, no. 1, pp. 33-36, 2003.

[81] J. Schneck, J. P. Fagot, P. Sekula, B. Sassolas, J. C. Roujeau, and M. Mockenhaupt, "Effects of treatments on the mortality of Stevens-Johnson syndrome and toxic epidermal necrolysis: a retrospective study on patients included in the prospective EuroSCAR study," Journal of the American Academy of Dermatology, vol. 58, no. 1, pp. 33-40, 2008.

[82] M. Aihara, Y. Kano, H. Fujita et al., "Efficacy of additional i.v. immunoglobulin to steroid therapy in Stevens-Johnson 
syndrome and toxic epidermal necrolysis," The Journal of Dermatology, vol. 42, no. 8, pp. 768-777, 2015.

[83] M. J. Koh and Y. K. Tay, "Stevens-Johnson syndrome and toxic epidermal necrolysis in Asian children," Journal of the American Academy of Dermatology, vol. 62, no. 1, pp. 54-60, 2010.

[84] H. Y. Lee, Y. L. Lim, T. Thirumoorthy, and S. M. Pang, "The role of intravenous immunoglobulin in toxic epidermal necrolysis: a retrospective analysis of 64 patients managed in a specialized centre," British Journal of Dermatology, vol. 169, no. 6, pp. 1304-1309, 2013.

[85] T. A. Chave, N. J. Mortimer, M. J. Sladden, A. P. Hall, and P. E. Hutchinson, "Toxic epidermal necrolysis: current evidence, practical management and future directions," British Journal of Dermatology, vol. 153, no. 2, pp. 241-253, 2005.

[86] J. M. Arévalo, J. A. Lorente, C. González-Herrada, and J. Jiménez-Reyes, "Treatment of toxic epidermal necrolysis with cyclosporin A," The Journal of Trauma and Acute Care Surgery, vol. 48, no. 3, pp. 473-478, 2000.

[87] E. Robak, T. Robak, J. Góra-Tybor et al., “Toxic epidermal necrolysis in a patient with severe aplastic anemia treated with cyclosporin A and G-CS," Journal of Medicine, vol. 32, no. 1-2, pp. 31-39, 2001.

[88] R. Rai and C. R. Srinivas, "Suprapharmacologic doses of intravenous dexamethasone followed by cyclosporine in the treatment of toxic epidermal necrolysis," Indian Journal of Dermatology Venereology and Leprology, vol. 74, no. 3, pp. 263-265, 2008.

[89] S. Zimmermann, P. Sekula, M. Venhoff et al., "Systemic immunomodulating therapies for Stevens-Johnson syndrome and toxic epidermal necrolysis: a systematic review and meta-analysis," JAMA Dermatology, vol. 153, no. 6, pp. 514-522, 2017.

[90] J. St. John, V. Ratushny, K. J. Liu et al., "Successful use of cyclosporin A for Stevens-Johnson syndrome and toxic epidermal necrolysis in three children," Pediatric Dermatology, vol. 34, no. 5, pp. 540-546, 2017.

[91] C. González-Herrada, S. Rodríguez-Martín, L. Cachafeiro et al., "Cyclosporine use in epidermal necrolysis is associated with an important mortality reduction: evidence from three different approaches," Journal of Investigative Dermatology, vol. 137, no. 10, pp. 2092-2100, 2017.

[92] S. Mohanty, A. Das, A. Ghosh, A. Sil, R. C. Gharami, and D. Bandyopadhyay, "Effectiveness, safety and tolerability of cyclosporine versus supportive treatment in Stevens-Johnson syndrome/toxic epidermal necrolysis: a record-based study," Indian Journal of Dermatology, Venereology and Leprology, vol. 83, no. 3, pp. 312-316, 2017.

[93] Y. K. Heng, H. Y. Lee, and J. C. Roujeau, "Epidermal necrolysis: 60 years of errors and advances," British Journal of Dermatology, vol. 173, no. 5, pp. 1250-1254, 2015.

[94] M. Mockenhaupt, "Stevens-Johnson syndrome and toxic epidermal necrolysis: clinical patterns, diagnostic considerations, etiology, and therapeutic management," Seminars in Cutaneous Medicine and Surgery, vol. 33, no. 1, pp. 10-16, 2014. 


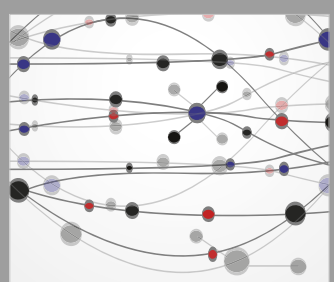

The Scientific World Journal
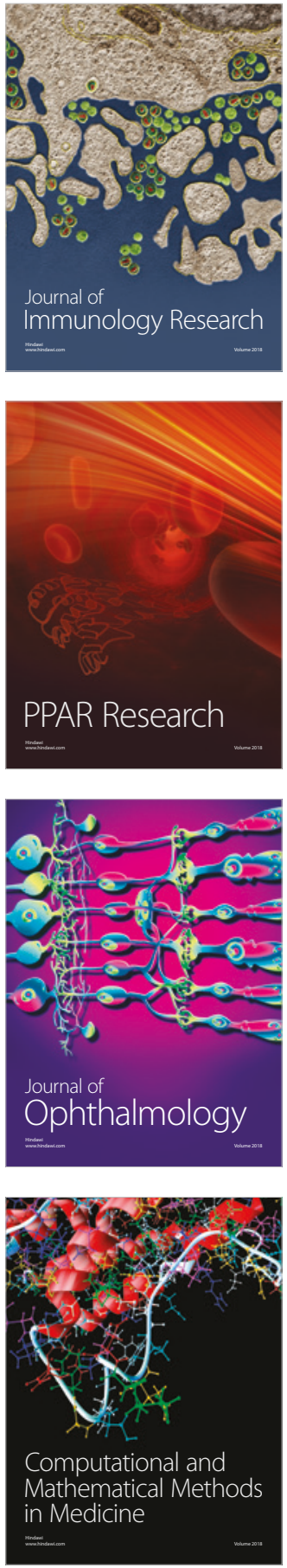

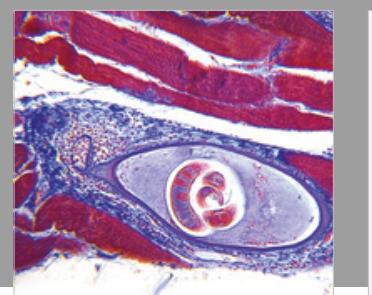

Gastroenterology Research and Practice

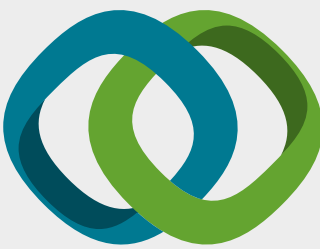

\section{Hindawi}

Submit your manuscripts at

www.hindawi.com
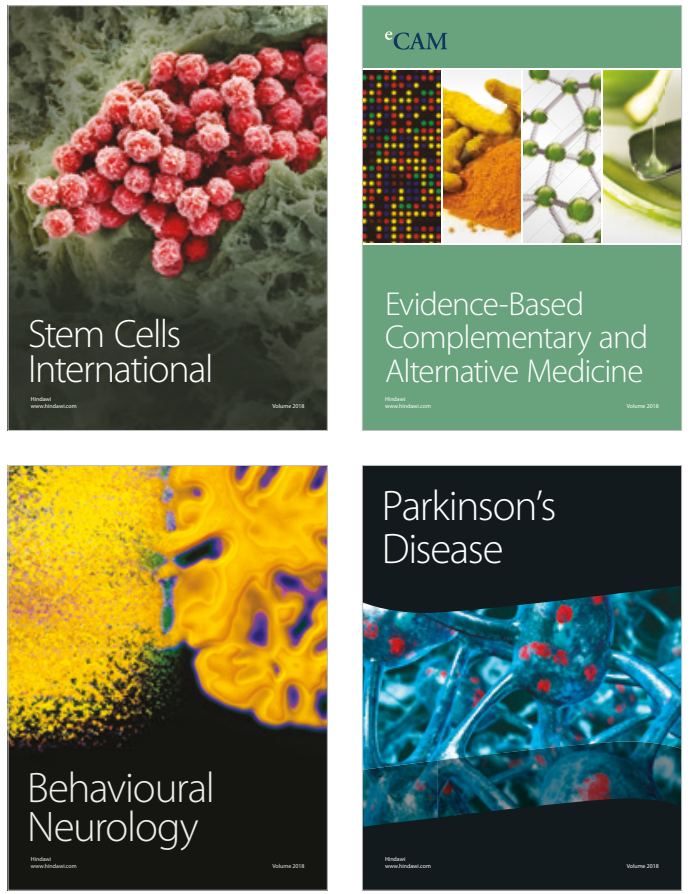

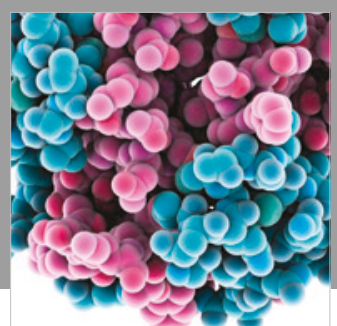

ournal of

Diabetes Research

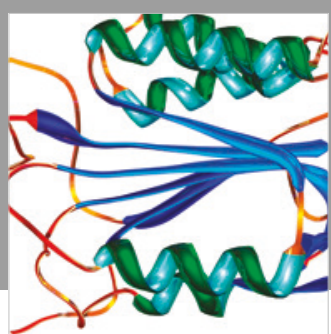

Disease Markers
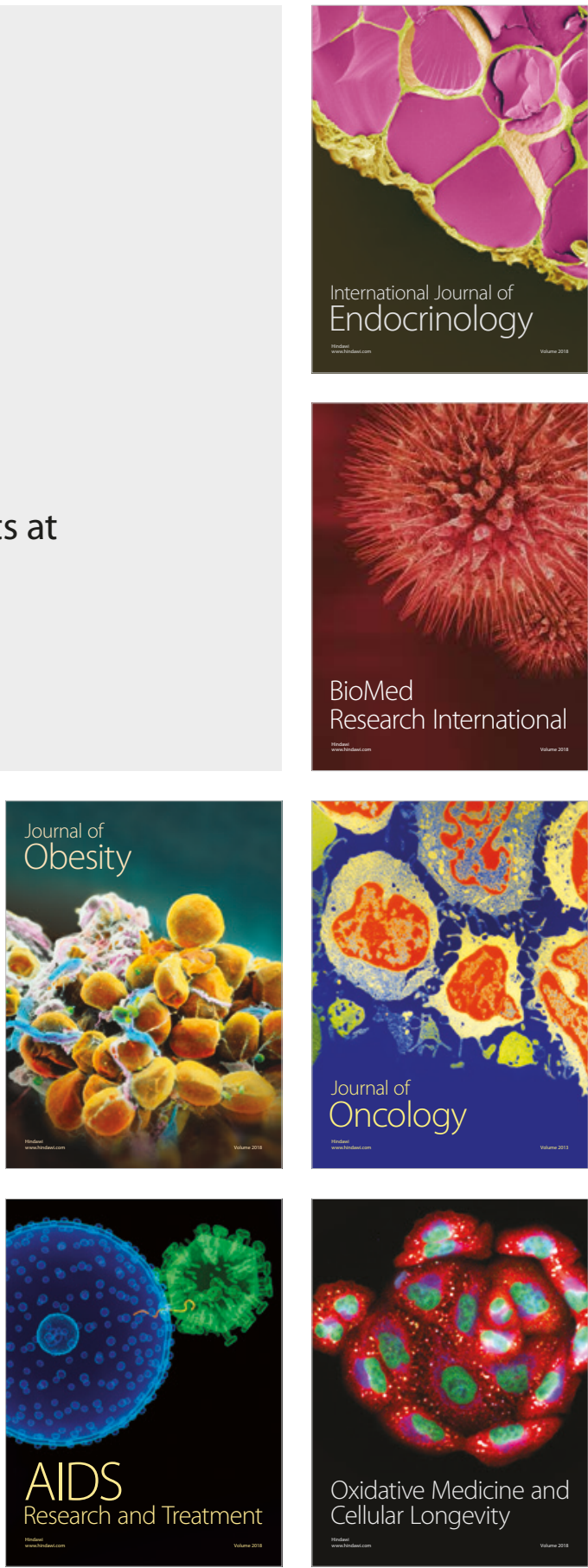